\title{
A REVOLUÇÃO NA ÉTICA E NA METAFÍSICA CAUSADA PELA NEUROCIÊNCIA, BIOTECNOLOGIA E PELO DESENVOLVIMENTO TECNOLÓGICO EM GERAL
}

\author{
Cinara Nabra
}

UFRN

RESUMO: O objetivo do presente artigo é discutir a influência do desenvolvimento tecnológico em geral, e da neurociência e da biotecnologia em particular, na discussão ética contemporânea. Mostramos então que do advento da pílula anticoncepcional até a discussão atual (em parte ainda ficcional) do enhancement e do moral enhancement, as novas tecnologias tem desafiado crenças e visões morais estabelecidas e têm colocado novos e importantes desafios para a reflexão ética. $O$ que pretendemos mostrar aqui é que o desenvolvimento científico e tecnológico que se acelera no final do século XX e início do século XXI, especialmente as pesquisas e técnicas usadas na neurociência e na biotecnologia, estão revolucionando a metafísica e a ética. Discutiremos aqui dois pontos, 1) a influência da neurociência na ética e na metafísica e 2) A influência da biotecnologia na ética e na metafísica.

\begin{abstract}
The purpose of this paper is to discuss the influence of technological development in general, and of the neuroscience and biotechnology in particular, in the contemporary ethical discussion. We show that the advent of the contraceptive pill to the current discussion (in part even fictional) of the enhancement and of the moral enhancement, the new technologies have challenged some established beliefs and moral views and have placed new and important challenges for ethical discussion. What we want to show here is that the scientific and technological development, accelerated in the late twentieth century and in the early twenty-first century, especially the research annd techniques used in neuroscience and biothecnology, are revolutionizing the metaphysics and ethics. Here, we discuss two points: 1). the influence of neuroscience on ethics and metaphysics and 2). the influence of biotechnology on ethics and metaphysics.
\end{abstract}




\section{A revolução na ética e na metafísica causada pela neurociência e pela biotecnologia}

a) A influência da neurociência na ética e na metafísica

A neurociência tem ajudado a lançar luzes na discussão de vários temas filosóficos, entre eles própria questão da moralidade e dos sentimentos morais, além de questões clássicas da investigação filosófica, como o livre arbítrio e o tema dos dilemas morais.

Os dilemas morais são um problema que se inscreve na filosofia contemporânea a partir de Philippa Foot ${ }^{1}$ com seu artigo The Problem of Abortion and the Doctrine of the Double Effect (O problema do aborto e a doutrina do duplo efeito). A discussão dos dilemas morais foi retomada por Judith Thomson $^{2}$ e centenas de outros filósofos no final do século passado, mas a partir do início do século XXI, quando surgiram técnicas de mapeamento cerebral como mapeamento por ressonância magnética (fMRI) e técnicas de estimulação cerebral, como estimulação magnética transcranial (TMS), uma transformação ocorreu no próprio modo de tratar e pesquisar a questão dos dilemas morais.

Em um artigo que de certa forma estabelece um novo paradigma para o tratamento de questões filosóficas Joshua Greene estuda dilemas morais que envolvem a questão de decidir entre matar ou deixar morrer uma ou mais pessoas para que mais possam sobreviver ${ }^{3}$. Greene aplica a técnica da ressonância magnética $(f m r l)$ a fim de observar o comportamento cerebral dos

\footnotetext{
1 Foot, Philippa "The Problem of Abortion and the Doctrine of the Double Effect" Oxford Review V.5 (1967): 5-15, republicado na coletânea de artigos de Foot, Philippa Virtudes and Vices (Oxford: Clarendon Press, 2009) p.20- 32.

2 Thomson, Judith Jarvis, The Trolley Problem, 94 Yale Law Journal 1395-1415 (1985)

3 Greene, J.D., Sommerville, R.B., Nystrom, L.E., Darley, J.M., \& Cohen, J.D. "An fMRI investigation of emotional engagement in moral Judgment". Science, Vol. 293, Sept. 14 (2001): 2105-2108.
} 


\section{Dossiê Naturalismo, Dissertatio - Volume Suplementar 02 | UFPel [2015]}

voluntários na experiência. O resultado, diz Greene, ajuda a clarificar alguns surpreendentes padrões de julgamento moral observados pelos filósofos contemporâneos. Segundo Greene há nestes dilemas uma tensão entre as perspectivas utilitarista e deontológicas, e estas perspectivas em filosofia moral refletem uma tensão mais fundamental que vem da estrutura do cérebro humano.

Segundo ele as respostas sócio emocionais que herdamos dos nossos ancestrais primatas, modelada e refinada pela cultura, é a base das proibições absolutas de caráter deontológico. Por outro lado o cálculo moral definido pelo utilitarismo só foi possível pelas estruturas do lóbulo frontal que evoluíram mais recentemente e que sustentam o pensamento abstrato e controle cognitivo complexo. A conclusão a que chega Greene é a de que há na realidade um conflito entre estes dois padrões de julgamento (deontológico e utilitarista) em nosso cérebro. A proximidade e o contato físico no caso do dilema do "homem forte" tenderiam a gerar uma resposta mais emocional, enquanto que a ausência de proximidade e contato no segundo caso tenderia a gerar uma resposta mais cognitiva. Interessantemente, para Greene, as respostas emocionais tenderiam a estar associada a deontologia e as respostas cognitivas tenderiam a estar associadas ao utilitarismo. O suporte para tal hipótese veio de experiências aonde foi utilizado a functional magnetic resonance imaging (fmri), imagem funcional de ressonância magnética.

Há muita discussão sobre se as conclusões a que Greene chega no seu estudo estão ou não corretas, mas o grande mérito de Greene não está, me parece, nas conclusões de sua pesquisa e sim na porta que se abre para a aquisição de um novo método para o fazer filosófico. A partir de seus estudos surge a possibilidade de que as questões éticas sejam discutidas não apenas através da argumentação, mas também através da experimentação cientifica. 
Aqui, na questão dos dilemas morais, fica claro, entretanto, que a neurociência não pode nos dar a resposta ética que procuramos, ou seja, "o que devemos fazer em tais casos?" embora ela nos ajude a responder a questão sobre "como fazemos estes julgamentos?". A questão que permanece, então, é a de se este esclarecimento sobre como fazemos nossos julgamentos pode nos ajudar a responder a questão sobre como devemos fazer estes julgamentos, e a resposta para isto requer um aporte ao is/ought (ser/dever) problema, e ao que chamamos de falácia naturalista na filosofia, ou seja, derivar um dever do ser.

Os estudos da neurociência, ao mostrar como as pessoas resolvem dilemas, poderiam nos dar um insight sobre como devemos resolver estes dilemas? Se quisermos inferir destes estudos uma resposta para a pergunta "o que devo fazer?" não estaríamos cometendo a chamada falácia naturalista? A resposta para isto, me parece, está em aceitar que a falácia naturalista é de fato uma falácia, ou seja, aceitar que não podemos derivar o dever ser do ser, e portanto que a ordem empírica não pode fundar a moralidade, mas não concluir, em função disto, que a ordem do dever ser não tenha nada a aprender com a ordem empírica.

Este modelo me parece que está em consonância com o que Kant sugere na Fundamentação da Metafísica dos Costumes ${ }^{4}$ quando ele nos diz que a Ética divide-se em dois campos, uma parte inteiramente racional e uma parte empírica, sendo a parte racional denominada moral e a parte empírica denominada antropologia pratica. A relação entre as duas é esclarecida por Kant:

As leis morais com seus princípios, em todo conhecimento prático, distinguem-se portanto de tudo o mais em que exista

4Kant, Immanuel Groundwork of the Metaphysics of Morals (Cambridge: Cambridge University Press,1997) p.3. 
qualquer coisa de empírico, e não só se distinguem essencialmente, como também toda a filosofia moral assenta inteiramente na sua parte pura que aplicada ao homem, não recebe um mínimo que seja do conhecimento do homem (antropologia) mas fornece-lhe como ser racional leis a priori. É verdade que estas exigem ainda uma faculdade de julgar apurada pela experiência, para, por um lado, distinguir em que caso elas tem aplicação e, por outro, assegurar-lhes entrada na vontade do homem e eficácia na sua prática. $O$ homem, com efeito, afetado por tantas inclinações é na verdade capaz de conceber a ideia de uma razão pura pratica, mas não é tão facilmente dotado da força necessária para tornar eficaz in concreto no seu comportamento.

A visão de Kant parece ser a de que a lei moral não precisa de nenhum elemento empírico para ser estabelecida, ou seja, a fonte da lei moral é efetivamente a priori. Por outro lado a aplicabilidade da lei moral é, evidentemente, empírica, ou seja, devemos aplicar os princípios da moralidade no mundo tal e qual ele é. E ai, então, necessitamos do conhecimento empírico, por duas razoes, segundo Kant:

a) Para saber em que casos a lei moral se aplica, ou seja, para sabermos quando estamos diante de uma situação que não é trivial e que envolve uma decisão moral, e principalmente

b) Para assegurar que a lei moral seja aceita pela vontade dos homens e seja eficaz, ou seja, é necessário o conhecimento empírico sobre os costumes dos povos e sobre como os indivíduos agem para que sejamos capazes de tentar compreender como os homens julgam moralmente e quais são as motivações humanas, tornando a tarefa de difundir a moralidade mais eficaz.

E é exatamente em função do ponto b) que se tornam relevantes os estudos que vem da neurociência sobre dilemas morais e sobre como julgamos e tomamos nossas decisões morais. Não se trata de entender como tomamos nossas decisões para derivar disto uma moralidade, ou várias moralidades, mas 
de entender como tomamos decisões morais para que possamos vir a tomar nossas decisões morais mais em consonância com os princípios do dever.

O que isto significa? No modelo clássico kantiano a vontade humana é cindida entre razão pura e sensibilidade, sendo estas duas (razão pura e sensibilidade) fontes distintas de máximas (princípios subjetivos da ação) que algumas vezes estão em oposição uma a outra. Assim, por exemplo, enquanto a razão pura nos diz que é irracional estabelecer uma lei universal de mentira, a sensibilidade pode nos levar a tentar abrir uma exceção a nosso favor na universalidade da lei, em função, por exemplo, do nosso próprio bem estar. No modelo Kantiano o que nos faz agir mal, ou imoralmente, não é uma malignidade de alto grau (escolher fazer o contrário do que sabemos que deve ser feito precisamente porque sabemos que isto é o contrário do que deve ser feito) mas sim, uma espécie de akrasia, a fragilidade da natureza humana, que sempre acha ocasião para tentar abrir exceções a nosso favor na regra que sabemos universal.

Se assim é o problema da imoralidade no mundo estará muito mais ligado a questão da motivação do que poderíamos suspeitar, e se este é o caso, os estudos da neurociência que lançam luzes sobre o modo como fazemos nossos julgamentos morais, e como justificamos estes julgamentos, tem um lugar fundamental nos estudos de ética contemporânea, não para determinar o que devemos fazer, mas para que conhecendo as motivações humanas e como fazemos julgamentos morais sejamos mais capazes de desenvolver nossa capacidade de agir de acordo com os princípios morais que aceitamos, mas que muitas vezes não conseguimos seguir em função exatamente da fraqueza da vontade.

Assim a incorporação de métodos empíricos vindos principalmente da neurociência e da psicologia experimental significa, antes de tudo, 


\section{Dossiê Naturalismo, Dissertatio - Volume Suplementar 02 | UFPel [2015]}

compreender que nenhuma teoria normativa da ética pode dispensar, para efeitos da sua aplicabilidade, o conhecimento empírico, especialmente o conhecimento que pode ser obtido através dos experimentos neurocientíficos sobre o modo como fazemos julgamentos morais e os mecanismos neurais envolvidos nestes julgamentos.

\section{b) A Influência da biotecnologia na ética e na metafísica}

A biotecnologia tem mudado a face do mundo, especialmente a partir da segunda metade do século XX, e com a filosofia não podia ser diferente. Uma das grandes mudanças provocadas pela biotecnologia, ainda no século passado, veio com a introdução da pílula anticoncepcional no início dos anos 60. Com ela as mulheres não estavam mais condenadas a necessariamente procriar após praticar sexo, fato que contribuiu enormemente para a revolução cultural que ocorreu nos anos 60 e para a chamada "libertação feminina".

A invenção da pílula anticoncepcional, e as transformações que ocorreriam a partir da sua introdução na vida quotidiana das mulheres não passou desapercebida para a Filosofia. Em um texto surpreendente de 1972, denominado Contraception and Chastity ${ }^{5}$, Elisabeth Anscombe afirma:

Eu peço primeiro que vocês contemplem a mudança fantástica que ocorre na posição das pessoas em relação a ter filhos por causa da invenção de métodos eficientes de contracepção. Vejam. O que não pode ser de outra forma nós aceitamos, e então aceitamos a morte e a infelicidade. Mas possibilidade destrói a mera aceitação. E assim é com a possibilidade de praticar sexo e não procriar. Este poder é agora colocado nas mãos das mulheres, elas não necessitam mais ter filhos quando não querem e ainda assim pode manter seus companheiros.

${ }^{5}$ Anscombe, Elizabeth "Contraception and Chastity," The Human World, 9 (1972): 41-51. Disponível em http://www.orthodoxytoday.org/articles/AnscombeChastity.php 
Neste artigo Anscombe vai condenar moralmente o uso da pílula anticoncepcional a partir de uma visão cristã. Ela continua, afirmando ${ }^{6}$ :

\begin{abstract}
Não existe uma coisa que seja um ato sexual casual e sem significado. Isto acontece porque sexo diz respeito a transmissão da vida...Aqueles que tentam abrir espaço para o sexo como um mero gozo casual pagam o preço: eles se tornam rasos (shallow). Eles desonram seus corpos, vulgarizando aquilo que é conectado com a origem da vida humana.
\end{abstract}

As conclusões a que Anscombe chega estão longe de ser consensuais, mas a sua percepção de que algo extremamente relevante a nível comportamental e moral estaria ocorrendo com a invenção da pílula anticoncepcional, e que de algum modo o tema deveria ser tratado filosoficamente, estava certa.

A invenção da pílula anticoncepcional foi a primeira de uma série de inovações que só foram possíveis com o avanço da biotecnologia e que mudaram, estão mudando e mudarão ainda muito mais o mundo tal como o conhecemos, trazendo profundas implicações e desdobramentos filosóficos. Com o desenvolvimento da pílula anticoncepcional a reprodução deixa de ser um acontecimento meramente natural, e deixa de ser uma consequência necessária do exercício da sexualidade, passando a ser controlada pelos homens através de um procedimento biotecnológico, no caso, a síntese da Norentidrona, o composto ativo base do primeiro contraceptivo oral sintético. Mas qual a relevância filosófica disto?

${ }^{6}$ lbid., 


\section{Dossiê Naturalismo, Dissertatio - Volume Suplementar 02 | UFPel [2015]}

Em uma conclusão distinta da conclusão a que chegou Anscombe em 1972 parece que o controle humano da reprodução através da biotecnologia, com a reprodução humana não sendo mais a consequência necessária e inevitável do sexo, inaugura, no final do século $\mathrm{XX}$, o processo de transformação da natureza humana que já começa a marcar, e provavelmente será a grande marca do milênio. Uma outra marca importante deste processo acontece em 1978, quando nasce em Oldham, grande Manchester, Louise Brown, o primeiro bebê a nascer através de fertilização artificial. Este nascimento marca o momento, na história humana, em que o sexo deixa de ser a condição necessária para a reprodução da vida humana, ou seja, o momento em que os seres humanos deixam de necessitar do sexo para a criação da vida. Neste momento, quando sexo e reprodução se separam, de modo que a espécie humana pode manter sua existência sem depender mais de sexo para isto, a ideia de natureza bumana se modifica para sempre.

Nos anos seguintes as descobertas cientificas na engenharia genética se avolumariam. Da clonagem ao PGD (Diagnóstico genético pre natal) abrese cada vez mais a possibilidade de que se escolham as características genéticas dos futuros membros da espécie humana. Esta escolha, que no momento já pode acontecer por razoes terapêuticas, no caso em que embriões com certas características são selecionados para nascer a fim de suprir as necessidades de material biológico necessário para salvar a vida de seus irmãos, por exemplo, poderá em breve ser estendida para outras características, e com isso, como nos adverte Habermas, a transformação da natureza humana será radical. Segundo Habermas ${ }^{7}$

A manipulação do genoma humano, que está sendo progressivamente decodificado, e as esperanças de alguns

\footnotetext{
${ }^{7}$ Habermas, Jurgen The future of human nature (Cambridge: Polity Press, 2003) p.42
} 
cientistas de que em breve tomaremos o curso da evolução em nossas mãos, acima de tudo aniquila a distinção categórica entre o subjetivo e o objetivo, aquilo que cresce naturalmente e aquilo que é fabricado, a medida em que se estendem para regiões que, até agora, nós não podíamos comandar. O que está em jogo é a desdiferenciação, através da biotecnologia, de distinções categoriais profundamente enraizadas, que até agora nós tínhamos assumido, na descrição que fazemos de nós mesmos, como sendo invariáveis.

Tenha ou não Habermas razão em suas conclusões, o fato é que a revolução biotecnológica em pleno curso pode transformar radicalmente a natureza humana. O prospecto do enhancement, ou seja, do aprimoramento humano através de meios biotecnológicos, pode produzir a transformação mais radical, e talvez a mais rápida, até agora acontecida na espécie humana.

Nick Bostron , um dos principais pensadores transhumanistas, define transhumanismo ${ }^{8}$ como sendo um modo de pensar sobre o futuro que é baseado na premissa que a espécie humana na sua forma corrente não representa o fim de nosso desenvolvimento mas sim, uma fase ainda jovem. Transhumanistas veem a natureza humana como algo que está sendo construído, um começo, que nós devemos aprender a remodelar em modos desejáveis. Segundo Bostron o estágio atual da humanidade não é necessariamente o estágio final da evolução. Os transhumanistas esperam que através do uso responsável da ciência, tecnologia e outros meios racionais nós poderemos nos tornar poshumanos, seres com capacidades muito maiores do que nós atualmente temos.

Não é possível predizer agora qual o futuro da natureza humana. Mas independentemente disto o que não pode ser negligenciado neste início de

8 Bostron ,Nick "Transhumanist Values" Review of Contemporary Philosophy, Vol. 4, May (2005), disponivel em http://www.nickbostrom.com/ethics/values.html 


\section{Dossiê Naturalismo, Dissertatio - Volume Suplementar 02 | UFPel [2015]}

milênio é o potencial da biotecnologia para transformar o mundo em que vivemos e também para influenciar profundamente a reflexão ético/filosófica.

\section{A Revolução em curso na ética e na metafísica}

Não é apenas a discussão da natureza humana, mas também outras questões tradicionais da metafisica como as do livre-arbítrio e da imortalidade da alma, entre outras, que se recolocam a partir do desenvolvimento tecnológico/cientifico e das perspectivas que se abrem a partir deste desenvolvimento, especialmente com os estudos e pesquisas que vem da neurociência e da biotecnologia.

Os experimentos de Libet, ainda na década de 80 , sugerem que processos inconscientes no cérebro iniciam os atos de nossa vontade, e que portanto, não é o livre arbítrio o responsável por isto9 . Mais recentemente foram publicados três trabalhos, todos de um grupo de pesquisadores vinculados ao Instituto Max Plank, que de certo modo pretendem corroborar, através de experimentos, a ideia de que o livro arbítrio não existe.

Argumentei longamente em outro artigo que não é correta a interpretação tradicional de que estes artigos mostrariam que o livre arbítrio não existe ${ }^{10}$. Porém, o que me interessa aqui, independentemente de qual for a nossa interpretação do experimento, é apontar que, seja qual for a conclusão a

\footnotetext{
${ }^{9}$ Os três artigos a que me refiro são; SOON, C.; BRASS, M.; HEINZE, H.; HAYNES, J. D. "Unconscious determinant of free decisions in the human brain". Nature v. 11 n..5, 2008, p. 543-545. HAYNES, J. D. "Decoding and predicting intentions". Ann. N.Y. Acad. Sci. 1224, 2011, p. 9-21. BODE, S.; HANXI H. E., A.; SOON, C. S.; TRAMPEL, R.; TURNER, R.; HAYNES, J. D. "Tracking the Unconscious Generation of Free decisions Using Ultra-High Field fMRl”. Plos One v. 6 n. 6, 2011, p. 1-13. A propósito desta discussão ver meu artigo: NAHRA, Cinara $A$ neurociência não prova que o livre arbitrio não existe em COITINHO, Denis e HOBUSS, João Sobre a Responsabilidade (Pelotas: NEPFIL online, 2014) p. 175194 no qual discuto em detalhes os artigos referidos, mostrando que não é verdade que estes experimentos seriam capazes de provar a não existência do livre arbítrio.

${ }^{10}$ Nahra, Ibid
} 
que se chegue, a filosofia já não pode mais dispensar experimentos científicos para discutir questões filosóficas, mesmo as mais clássicas. Por outro lado, as próprias questões filosóficas clássicas estão sujeitas a se transformar a partir do desenvolvimento científico e dos desafios e questões que este coloca. A discussão sobre o enhancement que surge com força no universo filosófico no início do século XXI é uma destas questões. Na sua esteira surge a discussão sobre a imortalidade do corpo, através do trabalho de Hans Jonas, que critica a possibilidade, defendendo os benefícios da mortalidade, e John Harris, que, ao contrário, discute os argumentos contrários e se coloca inteiramente favorável a hipótese.

Observe-se, então, a virada da questão metafísica clássica sobre a imortalidade da alma que acontece no início deste século. Enquanto no Fédon Platão ${ }^{11}$ associa o corpo a um túmulo que aprisiona a alma, de modo que a alma ao liberar-se dela continua sua trajetória imortal, na discussão contemporânea é exatamente o contrário que ocorre, ou seja, a possibilidade da imortalidade do corpo seria a garantia da perpetuação do self, e talvez, então, a única possibilidade de perpetuar o correlato do que se chama, na tradição, de alma. Parece então que, no início do III milênio estamos diante não do fim da metafisica, como muitos filósofos, entre eles Carnap e Heidegger anunciaram, mas, ao contrário, estamos à beira de uma revolução na metafísica, uma revolução que surge por duas razoes principais:

a) Pela necessidade que tem os filósofos de utilizar cada vez mais técnicas e métodos científicos no seu trabalho, a fim de evitar que este esteja em contradição com a experiência.

b) Pela impossibilidade que a reflexão filosófica fique alheia as técnicas que vem da neurociência e aos resultados da pesquisa nesta área e avanços

${ }^{11}$ Platão, Fedon em Platão, Diálogos (São Paulo: Hemus, 1981) 


\section{Dossiê Naturalismo, Dissertatio - Volume Suplementar 02 | UFPel [2015]}

tecnológicos e científicos que estão acontecendo e acontecerão a partir da biotecnologia.

Qual seria, então, o caráter desta revolução? Não se trata, em primeiro lugar, de substituir a reflexão filosófica pela experimentação cientifica. Como vimos nos casos analisados, a utilização das técnicas e dos métodos científicos não resolvem os problemas filosóficos. Ao contrário, a interpretação filosófica, e a divergência filosófica, continuam, e a contribuição da ciência acontece principalmente no sentido de lançar luzes a estes problemas e colocá-los em um outro patamar de discussão, um patamar em que a especulação filosófica tem de se valer da experimentação, embora não seja substituída por ou subsumida nesta. A grande vantagem deste método é que, se por um lado ele não garante a objetividade da ciência na filosofia, por outro evita a digressão vã que muitos classificam como diletantismo, ou dogmatismo.

Evoco nesta revolução que já se anuncia um certo espirito kantiano. Kant nos diz: ${ }^{12}$

\begin{abstract}
Desgostosos, pois, com o dogmatismo, que nada nos ensina, e também com o ceticismo, que nada nos promete, nem sequer a tranquilidade de uma ignorância permitida, solicitados pela importância do conhecimento de que temos necessidade e desconfiados, em virtude de uma longa experiência de tudo o que julgamos possuir ou que se nos oferece sob o título de razão pura, resta-nos apenas uma questão crítica, cuja solução pode orientar a nossa atitude futura: É a metafisica verdadeiramente possível?
\end{abstract}

A resposta de Kant a sua pergunta é ensaiada em um trecho a seguir dos Prolegômenos ${ }^{13}$ (p.165) quando nos diz:

${ }^{12}$ Kant, Prolegômenos (A 38) trad. de Artur Morão (Lisboa:Edições 70,s/d) p.35 
Mas embora tenha chegado incontestavelmente o tempo da decadência de toda metafisica dogmática, falta ainda muito tempo para se afirmar que o tempo da sua ressurreição, mediante uma crítica sólida e completa da razão, tenha, pelo contrário, surgido.

A meu ver Kant acerta no diagnóstico e erra no remédio. Um certo tipo de filosofia, um certo tipo de metafísica, a metafísica dogmática, está sim em decadência. A minha aposta, entretanto, é que há sim uma ressureição possível, que já está se desenhando e que virá não apenas de uma crítica completa da razão nos moldes kantianos mas a partir das novas tecnologias que surgem, das pesquisas empíricas que podem ajudar a elucidar questões filosóficas e com os desafios e novas questões que especialmente a neurociência e a biotecnologia têm trazido para a reflexão ética e filosófica.

Não acredito que chegará o dia em que a falácia naturalista deixará de ser uma falácia. Não penso também que devamos derivar o dever ser do ser. Mas já vejo claramente os indícios de que breve perceberemos que para transformar o dever em ser, ou seja, transformar o mundo em um lugar mais ético e com menos sofrimento, o conhecimento que a neurociência pode nos dar, de como os seres humanos julgam e agem moralmente, e o que acontece em nossos cérebros quando fazemos isto, será imprescindível. Assim como importante será também a ajuda da biotecnologia, como profetizam os defensores do moral enhancement, mas isto será assunto para outra hora.

\section{REFERÊNCIAS}

${ }^{13}$ Kant, Prolegômenos (A 191,192) trad. de Artur Morão (Lisboa: Edições 70, s/d) p.165 
ANSCOMBE , E. "Contraception and Chastity". The Human World, 9 (1972): 41-51. Disponível em

http://www.orthodoxytoday.org/articles/AnscombeChastity.php

BODE, S.; HANXI H. E., A.; SOON, C. S.; TRAMPEL, R.; TURNER, R.; HAYNES, J. D. "Tracking the Unconscious Generation of Free decisions Using Ultra-High Field fMRI”. Plos One v. 6 n. 6, 2011, p. 1-13

BOSTRON ,N. “Transhumanist Values”. Review of Contemporary Philosophy, Vol. 4, May (2005), disponível em http://www.nickbostrom.com/ethics/values.html

FOOT , P. The Problem of Abortion and the Doctrine of the Double Effect. Oxford Review V.5 (1967): 5-15

Virtudes and Vices (Oxford: Clarendon Press, 2009)

GREENE, J.D., SOMERVILLE R.B., NYSTROM, L.E., DARLEY, J.M., \& COHEN, J.D. "An fMRI investigation of emotional engagement in moral Judgment”. Science, Vol. 293, Sept. 14 (2001): 2105-2108.

HABERMAS, J. The future of human nature (Cambridge: Polity Press, 2003)

HAYNES, J. D. Decoding and predicting intentions. Ann. N.Y. Acad. Sci. 1224, 2011, p. 9-21.

KANT. Groundwork of the Metaphysics of Morals (Cambridge: Cambridge University Press,1997)

Prolegômenos (A 38) trad. de Artur Morão (Lisboa:Edições 70,s/d)

NAHRA, C. "A neurociência não prova que o livre arbítrio não existe" em COITINHO, D. e HOBUSS, J. Sobre a Responsabilidade (Pelotas: NEPFIL online, 2014) p. 175-194

PLATÃO, Fedon em Platão, Diálogos (São Paulo: Hemus, 1981)

SOON, C.; BRASS, M.; HEINZE, H.; HAYNES, J. D. "Unconscious determinant of free decisions in the human brain". Nature v. 11 n..5, 2008, p. 543-545.

THOMSON , J. "The Trolley Problem”. 94 Yale Law Journal 1395-1415 (1985) 